\title{
Fourth Ventricle Ependymal Tumor
}

National Cancer Institute

\section{Source}

National Cancer Institute. Fourth Ventricle Ependymal Tumor. NCI Thesaurus. Code C131593.

An ependymal tumor arising from the fourth ventricle of the brain. 